Notas Clínicas

\title{
La gammagrafía ósea en el granuloma eosinófilo
}

I. Núñez Cambre, S. Argibay Vázquez, J. Barandela Salgado, A. Sánchez Salmón, V. Pubul Núñez, A. Ruibal Morell

\section{Resumen}

- Propósito: La histiocitosis de células de Langerhans es una enfermedad rara, que clínicamente se presenta con un espectro muy amplio. Destacamos el manejo diagnóstico de la $\mathrm{HCL}$ con estudios gammagráficos, que son casi patognomónicos.

- Material y métodos: En este trabajo presentamos un caso de granuloma eosinófilo con una imagen típica en la gammagrafía ósea, lesión única hipercaptante en $5^{\circ}$ arco costal.

- Conclusiones: La gammagrafía ósea es útil en el diagnóstico de HCL y en el manejo de dichos pacientes.

Palabras clave:

Histiocitosis. Granuloma eosinófilo. Gammagrafía ósea.

Oncología, 2004; 27 (8):509-513 


\section{Summary}

- Purpose: Langerhans' cells histiocytosis (LCH) is an uncommon disease, presenting clinically with a very wide spectrum of symptoms. We point out the diagnostic procedure of $\mathrm{LCH}$ by means of scintigraphy studies, that is almost pathognomonic.

- Material and methods: We present a case of eosinoplilic granuloma with a typical bone scintigraphy, described in the literature as just one lesion with intense uptake in the 5 th rib.

- Conclusions: Bone scintigrapgy is useful for the diagnosis of LCH and the management of the patients.

Key words: Histiocytosis. Eosinophilic granuloma. Bone scintigraphy.

\section{Introducción}

La histiocitosis de células de Langerhans (HCL) es una enfermedad granulomatosa con una incidencia de $1 / 200.000$ por año en niños menores de 15 años'. Pasada la $3^{a}$ década de la vida es muy rara ${ }^{2}$. Su etiología y patogenia es desconocida, si bien estudios recientes han barajado diversas causas, entre las que destacan el origen microbiano, genético 0 incluso inmunitario. Inicialmente se pensaba que la proliferación de macrófagos (histiocitos) era la característica de esta enfermedad, pero actualmente se sabe que se trata de una proliferación reactiva o neoplásica de células de los sistemas mononuclear-fagocítico y células dendríti$\mathrm{cas}^{3}$. La célula dendrítica puede evolucionar a célula de Langerhans, caracterizada por la presencia de un antígeno de superficie (CDla), que reacciona con un anticuerpo monoclonal $\left(\mathrm{OKT}_{6}\right)$. Ante la sospecha clínica, el diagnóstico se basa en la demostración de células de Langerhans en la biopsia o citología de las lesiones, aunque no son patognomónicas de este proce$\mathrm{so}^{4}$. El diagnóstico de seguridad requiere la confirmación histológica caracterizada por la positividad para la $\mathrm{S} 100$ (constituye para algunos autores el mejor marcador) y CDla en la superficie de la célula o bien la presencia de gránulos de Birbëck (o cuerpos en raqueta) por microscopía electrónica de transmisión ${ }^{5}$.

La presentación clínica es extremadamente variable, desde la afectación ósea única (granuloma eosinófilo) que puede recuperarse por sí sola, hasta la multisistémica con fallo orgánico, que puede ser resistente a la quimioterapia. Las lesiones pueden desarrollarse en cualquier órgano, siendo el hueso, piel y ganglios linfáticos los tejidos que con mayor frecuencia se afectan.
La lesión ósea, única o múltiple, es la forma más frecuente de $\mathrm{HCL}$ localizada y puede tratarse de un hallazgo radiológico casual en un joven asintomático, aunque con frecuencia el paciente consulta por dolor.

Los métodos diagnósticos más utilizados son la radiología simple (detecta la mayoría de las lesiones óseas), la ecografía (evalúa la posible existencia de implicación de un órgano sólido abdominal), la TAC (precisa la localización), la RM (muy útil para definir extensión a tejidos blandos), la gammagrafía, la punciónaspiración con aguja fina y la biopsia de la lesión.

El pronóstico del proceso depende del número de órganos afectados y de su alteración funcional. Las lesiones localizadas, especialmente las óseas, pueden regresar espontáneamente o con tratamiento local (biopsia escisional), por lo que la conducta expectante está justificada. En la histiocitosis de células de Langerhans unisistémica se ha empleado radioterapia a dosis bajas, infusión intralesional de corticoides o fotoquimioterapia. El tratamiento de la enfermedad diseminada debe ser quimioterápico ${ }^{6}$.

\section{Caso clínico}

Mujer de 22 años en seguimiento desde infancia por bicitopenia (neutropenia y trombopenia) e hipergammaglobulinemia $\lg M$. Como antecedentes personales cabe destacar una perforación timpánica, sarampión hemorrágico y cistitis de repetición.

La paciente consulta por dolor punzante en costado izquierdo que precisa analgesia, con un estudio de radiología simple no patológico, por lo que el dolor se interpretó como muscular. 
Dada la persistencia durante más de un mes del cuadro clínico, no evidenciándose respuesta al tratamiento analgésico, la paciente es remitida a nuestro Servicio de Medicina Nuclear para valoración con gammagrafía ósea de cuerpo entero y estática de tórax. El rastreo corporal mostraba un foco de concentración selectiva del radiotrazador en $5^{\mathrm{a}}$ costilla de hemitórax izquierdo, sin alteraciones significativas en el resto del esqueleto. Posteriormente se realiza una TAC en la que se evidencia una lesión costal longitudinal de predominio osteolítico. La PAAF bajo control de TAC demuestra hallazgos citológicos indicativos de histiocitosis X (granuloma eosinófilo). Se completa el estudio con una ecografía de abdomen en la que se observa esplenomegalia gigante y moderada hepatomegalia, ambas con ecoestructura homogénea, y con radiología simple que esta vez sí evidencia lesión, de tipo mixto con predominio blástico en $5^{a}$ costilla izquierda. La médula ósea se encontraba libre de infiltración por granulomatosis de células de Langerhans.

Como terapéutica se aconsejó la realización de resección quirúrgica de arco costal, que es rechazada por la paciente. La conducta expectante está justificada, por lo que se procede al seguimiento clínico y radiológico con controles periódicos de TAC.

El estudio de TAC realizado tres meses después del diagnóstico, demostró la misma lesión osteolítica con tendencia a la regresión.

\section{Discusión}

Los términos de granulomatosis de células de Langerhans, histiocitosis de células de Langerhans, histiocitosis X, histiocitosis diferenciada, granuloma eosinófilo se aplican a una entidad clínico patológica específica, aunque muy variable, caracterizada y definida por la proliferación de células de Langerhans. Estas células han generado un gran interés desde su descripción por el Dr. Paul Langerhans en 1865 como una célula aurófila presente en la piel. Durante años se le consideró de la familia de los melanocitos, pero en 1977 se descubrió que expresaban moléculas del Complejo Mayor de Histocompatibilidad clase II y que jugaban un papel inmunológico. Hoy se sabe que es una de las células presentadora de antígenos más potentes ${ }^{7}$.

Hemos expuesto el caso clínico de una paciente joven, con patología hematológica ya conocida, que presentaba clínica en forma de dolor de meses de evolución que no remitía, precisando tratamiento analgésico de forma continuada y con radiología normal, lo que indujo a la realización de una gammagrafía ósea

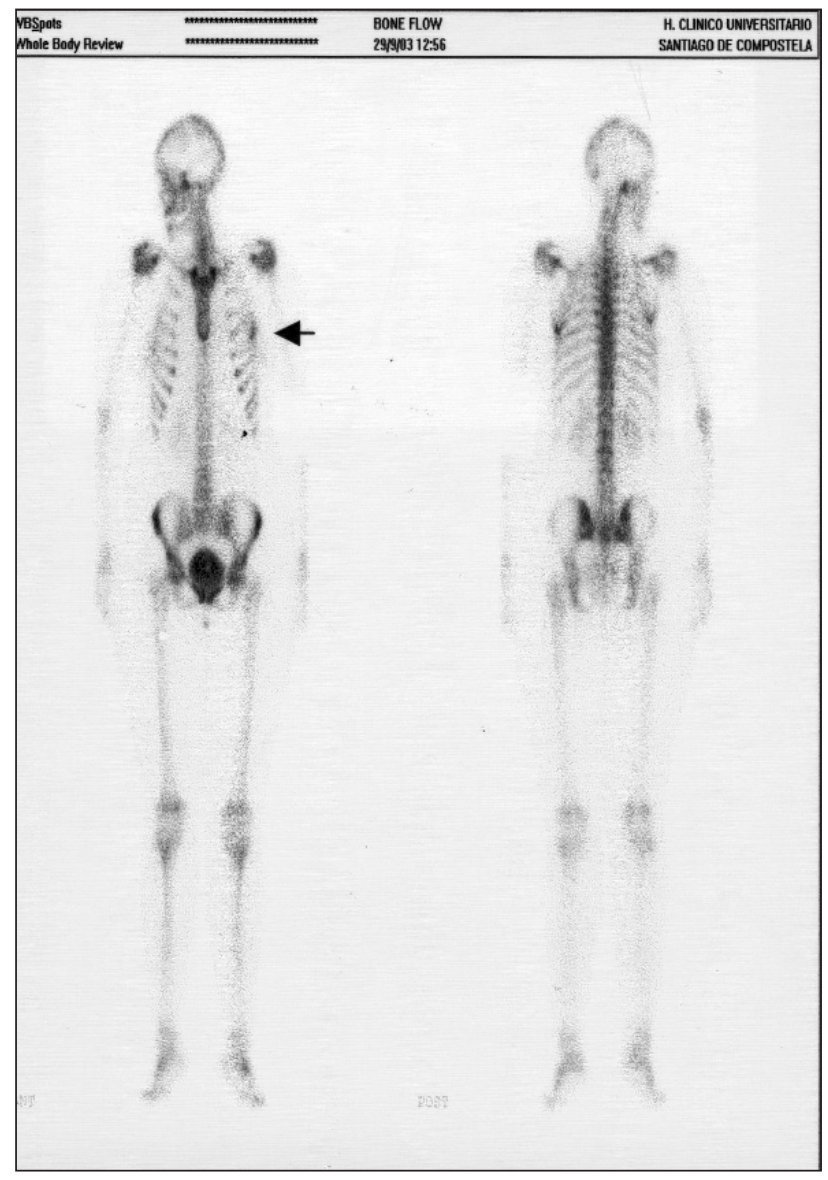

Fig. 1. Gammagrafía ósea de cuerpo entero. Se aprecia una hipercaptación a nivel de $5^{\circ}$ arco costal izquierdo, sin alteraciones en el resto del esqueleto.

con DPD-99mTc, exploración más empleada para la evaluación de la afectación ósea de todo el cuerpo. Dicha prueba se realiza a las dos horas tras la inyección intravenosa de aproximadamente $20 \mathrm{mCi}$ (740 $\mathrm{MBq}$ ) de DPD-99mTc, obteniendo imágenes planares de rastreo de cuerpo entero y estáticas centradas en tórax, realizándose en este caso proyecciones anterior, posterior y lateral. La gammagrafía demostró una lesión monostótica hipercaptante en $5^{\circ}$ arco costal izquierdo, evidente en el rastreo corporal (Fig. 1) y con mayor nitidez en los estudios estáticos de tórax (Fig. 2 y 3), sin anormalidades significativas en el resto del esqueleto. Desde nuestro Servicio, ante estos hallazgos, se recomendó radiología selectiva de la zona, obteniéndose imágenes que evidenciaron una lesión lítica solitaria a ese mismo nivel.

La gammagrafía ósea tiene, al contrario de lo que ocurre con la radiología simple, mayor sensibilidad en el diagnóstico de lesiones monostóticas que en las po- 


\section{Núñez Cambre y cols.}

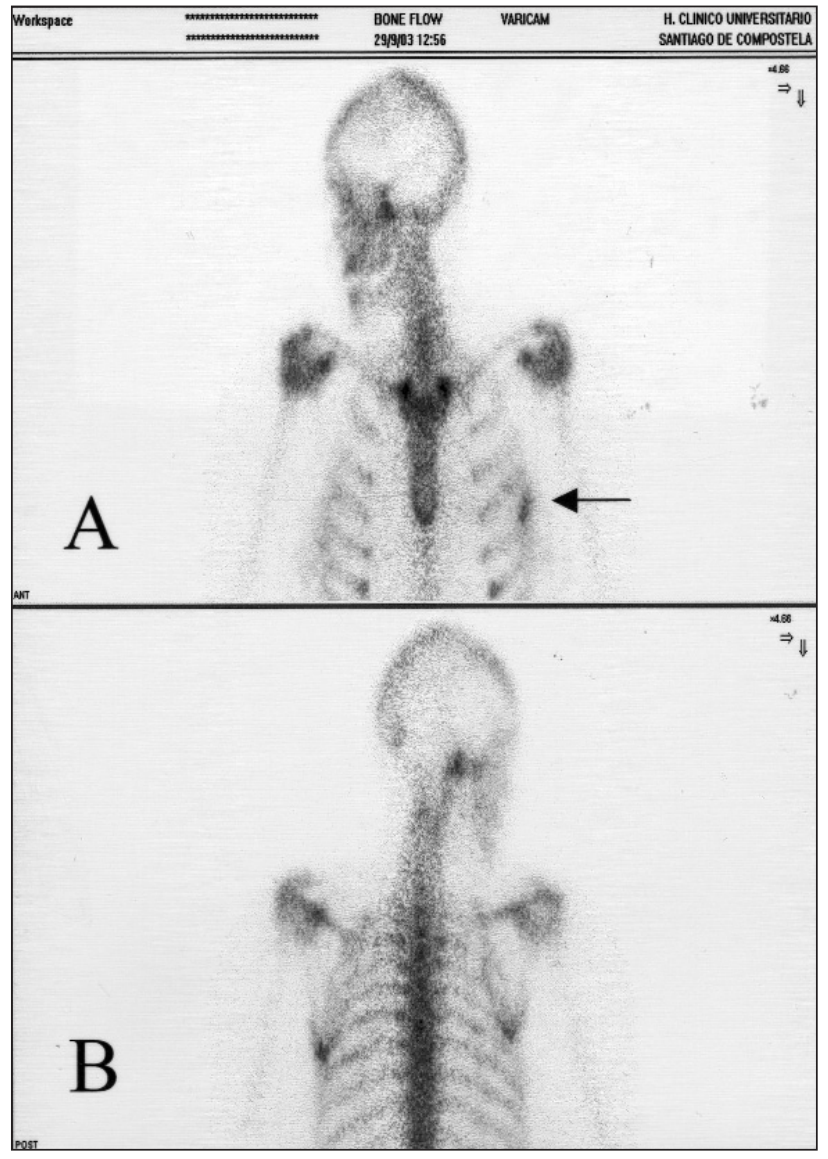

Fig. 2. Gammagrafía ósea estática de tórax. Lesión hipercaptante en $5^{\circ}$ arco costal izquierdo. A- proyección anterior. B- proyección posterior.

liostóticas. Sin embargo, existen controversias en cuanto a la exactitud diagnóstica de la gammagrafía ósea según la localización de la lesión. Algunos autores describen una mayor sensibilidad de esta última en las costillas, columna y pelvis y menor en el cráneo ${ }^{8}$. Otros grupos demuestran mayor exactitud a nivel de cráneo, mandíbula y huesos faciales ${ }^{9}$. En nuestra paciente la exploración gammagráfica y los hallazgos clínicos fueron compatibles con lo descrito en la literatura: lesión hipercaptante monostótica única en arco costal en una mujer joven con dolor punzante y enfermedad limitada a tejido óseo, localización, sintomatología y pruebas diagnósticas típicas del granuloma eosinófilo.

La radiología simple detecta lesiones osteolíticas en huesos largos y planos, en general sin reacción perióstica, con una localización preferente en cráneo, parrilla costal, mandíbula y pelvis ${ }^{10}$. Mientras que la TAC es útil para definir de forma precisa la extensión y localización, la RM lo es para lesiones más agresivas

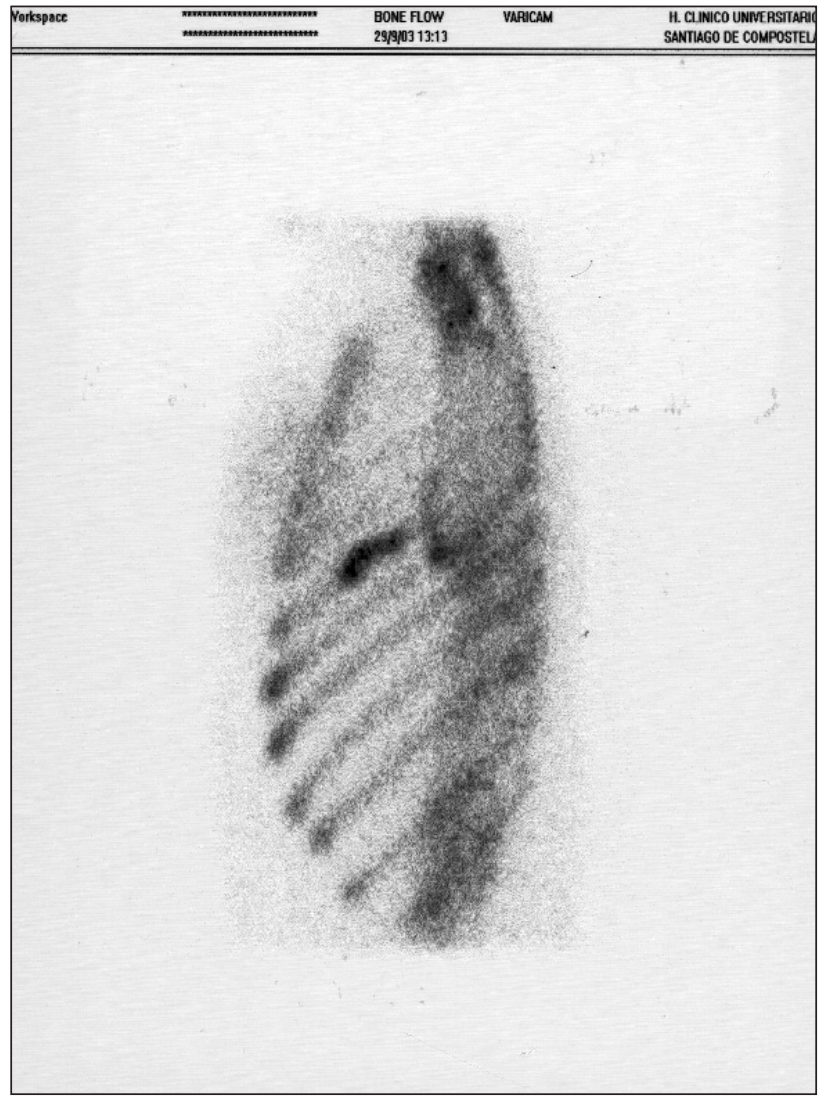

Fig. 3. Gammagrafía ósea de tórax, proyección lateral. Lesión en arco costal izquierdo. Se aprecia hipercaptación en dicha localización.

que afectan a tejidos blandos. A nuestra paciente se le completó el estudio con una ecografía, método de imagen que evalúa la posible afectación abdominal. Otros autores resaltan el papel importante de la gammagrafía con ${ }^{67} \mathrm{Ga}$ en el estudio de la distribución de esta enfermedad ${ }^{11}$, aunque no ha llegado a establecerse como exploración rutinaria.

Las técnicas de Medicina Nuclear ofrecen la gran ventaja de que en un mismo estudio se exploran todas las regiones anatómicas, siendo la gammagrafía ósea la prueba más utilizada y la primera realizada a nuestra paciente. Merece destacarse que los hallazgos permitieron sugerir la enfermedad. Trabajos recientes han introducido la gammagrafía de receptores de somatostatina (SS), dado que los linfocitos activados los expresan. Es una prueba útil en la detección de lesiones activas de $\mathrm{HCL}$, lo que puede jugar un papel relevante en el seguimiento y manejo de la enfermedad ${ }^{12}$. Sin embargo, esta exploración no se realizó en el caso presentado.

Podemos concluir diciendo que el diagnóstico de 
histiocitosis de células de Langerhans ósea, (granuloma eosinófilo) se ha basado no sólo en estudios anatomopatológicos compatibles con dicha enfermedad, sino también y fundamentalmente en las manifestaciones clínicas y en los hallazgos mediante técnicas radiológicas e isotópicas, en concreto la gammagrafía ósea, por lo que creemos necesario destacar su utilidad en el diagnóstico de esta entidad clínica y en su seguimiento.

\section{Correspondencia:}

Dra. I. Núñez Cambre

Servicio de Medicina Nuclear

Hospital Clínico Universitario de Santiago de Compostela Travesía de la Choupana, s/n

E-15706 Santiago de Compostela

E-mail: irianu@hotmail.com

\section{Bibliografía}

1. Thomas C, Donnadieu J, Emile JF, Brousse N. Langerhans cell histiocytosis. Arch Pediatr 1996; 3:63-9.

2. Aricó M, Egeler ME. Clinical aspects of Langerhans cell histiocytosis. Hematol Oncol Clin North Am 1998; 12:247-58.

3. Hervás I, Bello P, Fernández JM, González-Cabezas $P$, Flores D, Torres MJ, Cañete A, Pérez-Velasco R, Rivas A, Alonso J, Castel V, Mateo A. Gammagrafía ósea y gammagrafía de receptores de la somatostatina en pacientes pediátricos con histiocitosis de células de Langerhans ósea. Rev Esp Med Nucl 2003; 22:367-75.

4. Fauci AS, Braunwald E, Isselbacher KJ, Wilson JD, Martin JB, Kasper DL, Hauser SL, Longo DL. Principios de medicina interna. En: Enfermedades intersticiales del pulmón (Eds. Herbert Y. Reynolds), 14a ed. España: McGraw-Hill-Interamericana, pp. 1661-7.

5. Pena Pardo FJ, Banzo Marraco I, Quirce Pisano R, Hernández Allende R, Carril Carril JM. Gammagrafía ósea en la enfermedad de Erdheim-Chester.Rev Esp Med Nucl 2003; 22:253-6.

6. Cervera JL, Ferreiro C, Portell M. Histiocitosis de células de Langerhans del hueso temporal. Radiología 2003; 45:52.

7. Coppes-Zantinga A, Egeler RM. The Langerhans cell histiocytosis X files revealed. Br J Haematol 2002; 116:3-9.

8. Dogan AS, Conway JJ, Miller JH, Grier D, Battathiry MM, Mitchell CS. Detection of bone lesions in Langerhans cell histiocytosis: Complementary roles of scintigraphy and conventional radiography. J Pediatr Hematol Oncol 1996; 1:51-8.

9. Howarth DM, Mullan BP, Wiseman GA, Wenger DE, Forstrom LA, Dunn WL. Bone scintigraphy evaluated in diagnosis and staging Langerhans' cell histiocytosis and related disorders. J Nucl Med 1996; 37:1456-60.

10. Oriol A. Histiocitosis de células de Langerhans (histiocitosis X). JANO 1999; 57:70-80.

11. Franzius C, Sciuk J, Bremer C, Kempkes M, Schober $O$. Determination of extent and activity with radionuclide imaging in Erdheim-Chester disease. Clin Nucl Med. 1999; 24:252-5.

12. Calming U, Jacobsson H, Henter Jl. Detection of Langerhans cell histiocytosis lesions with somatostatin analogue scintigraphy. A preliminary report. Med Pediatr Oncol 2000; 35:462-7. 